\section{Feel for biological rhythms}

An Introduction "o Biological Rhythms. By J. D. Palmer. With contributions by F. A. Brown, Jr and L. N. Edmunds, Jr. Pp. xvi+373. (Academic: New York and London, August 1976.) \$19.50: $£ 11.90$.

THE author describes this as an introductory book, pitched at a level between popular books and technical treatises: these two stools are difficult to bridge. The enquiring student, to whom it is in part addressed, might find it difficult to evaluate for himself the evidence for many of the statements made: each chapter ends with some recommended further reading, but the text does not direct the reader specifically to the appropriate sources for the different assertions. This would indeed hardly be possible in a book with so wide a compass in such modest size.

Apart from general descriptions of the nature and properties of biological rhythms. circadian, lunar and annual, the author describes in more detail rhythms in unicellular and multicellular plants and animals, and the use of circadian clocks in animal, particularly in hird navigation, as well as some of the implications for man. The popular appeal is contributed in part by anecdotes of the background of some experimental investigations. but also by such journalistic epithets as "flamboyant" experiments and the "callous" decapitation of cockroaches. There is a similarly journalistic passage about the motivation behind human subjects for experiments, which in no way enhances the scientific value.

Little over half the book is written. however. by the author himself. It ends with two extended chapters, by F. A. Brown and by L. N. Edmunds, discussing the two rival theories: that biological rhythms depend essentially on subtle geophysical rhythms, or that they are due to an internal timing mechanism. Dr Brown's constant advocacy of the former hypothesis is familiar enough, but his chapter is the least readable in the book. A little of it is simply polemical. but the greater part consists of closely reasoned arguments demanding from the reader a highly critical attention. More than one interpretation can be put on many of the experiments described. hut it is convincingly shown that a wide range of organisms can respond to a variety of quite small geophysical influences whose detection was hitherto totally unfamiliar to animal physiologists.

Dr Edmunds in the concluding chapter avoids a polemical adherence to the endogenous theory hut considers various possibilities of its mode of operation. Simple and convincing evidence is given that. at least in some insects. the rhythmicity is controlled by a part of the central nervous system operating by the rclease of a chemical substance, and that in mammals and birds the suprachiasmatic nucleus, operating by way of the pineal, plays a dominant or at least an important role. With regard to the fundamental question of the underlying circadian escapement, which has been shown to be present even in single enucleated cells. the three major theories are outlined: theories depending on a biochemical feedback loop. on transcription along a DNA template, and on ions and ion transport in membranes. With the advantage of a limited field to cover, this chapter is perhaps the most successful in introducing biologists from outside this field to the major lines of thought: although in other respects, by virtue of the very broad coverage of different periodicities in such a wide range of organisms, the earlier chapters should be very helpful for those who want, as the author puts it, to get a "feel" for the subject.

J. N. Mills

J. $\Lambda^{\prime}$. Mills is Brackenbury Professor of Physiology at the University of Manchester. UK.

\section{Animal response to environmental parameters}

C'omparative Physiology of Animals: An Environmental Approach. By Richard W. Hill. Pp.xii +656 . (Harper and Row: New York and London. 1976.) $£ 9.90$.

AlTrer years with no suitable text for an undergraduate course in animal physiology, we are now confronted with a succession of such texts and the problem of choice. This latest offering. by Richard W. Hill, is a very readable book intended for students beginning their study of the subject. Hill places his emphasis on the animal in its natural environment and on the physiological responses to the various environmental parameters rather than on the fundamental mechanisms underlying these responses. The physiological principles and relationships are presented accurately but primarily in nonquantitative and descriptive terms. and the book should appeal to readers who favour this approach.

The scope is ambitious since it embraces all animal groups aside from protozoans and metazoan parasites. The chapter by chapter organisation is hased on physiological functions or environmental factors. The opening two chapters on organisms in the environment and on encrgy metabolism set the stage nicely for the following chapters on thermal relations. salt and water exchange. excretion. gas exchange and circulation. The book concludes with a serics of integrative chapters on oxygen deficiency. high altitude, diving, exercise and rhythmicity. These final chapters are particularly successful in tying together the carlier material while reinforcing the environmental theme of the book. The coverage of the various topics is comprehensive although occasionally somewhat repetitive (for example, the section of salt and water exchange). But students will appreciate the careful exposition of the concepts and the extensive use of appropriate experimental data illustrating the concepts. The morc inquisitive students, however, may be frustrated by the fact that practically none of these experiments are referenced and most are not identified with the names of the investigators involved. Potential subscribers are therefore forewarned to put their own knowledge of the literature in order before assigning this text to their students. Some readers may also be troubled by the absence of any detailed discussion of the neural and endocrine systems, and the consequent patchy and superficial treatment of the role these systems play in the physiological response to the environment. In spite of these omissions, I found the overall organisation and content of the book to be quite coherent. It is an excellent text particularly suited for courses attempting to bridge the gap between physiology and ecology.

This book is not without value for more advanced readers as well. Hill's emphasis on the animal's response to its natural situation should remind those of us who study 'non-laboratory' animals in the laboratory to design our experiments carefully with the objective heing to learn how these animals function in their natural milieu. Conversely, we must learn all we can of our particular animal's normal milieu in order to design useful experiments. These are also important lessons for students just beginning thrir studies in the field, and this book should serve that purpose well. while at the same time providing a sound introduction to animal physiology. Donald C. Jackson

Donald Jackson is Associate Professor of Medical Science at Brow'n LIniversity. Providence, Rhode Island. 